\title{
Ethical Issues in HSCT
}

\author{
Khaled El-Ghariani and Jean-Hugues Dalle
}

\subsection{Introduction}

Ethics is a branch of philosophy, and, like mathematics, moral philosophy does not give ready-made answers to questions but teaches how one could systematically analyse and resolve a problem. Philosophy's main tool, to achieve this, is logic, where accurate premises are linked together to support a conclusion within a sound and valid ethical argument (West 2009). This chapter aims to explain this process using examples from blood and marrow transplantation practices.

Ethical discourse requires a theory of ethics (Thompson 2005). One requires a landmark to understand their ethical position. One needs to know on what basis one can decide if an action is wrong or right, bad or good; a theory of ethics should help this. It will also allow better understanding of common threats to ethics such as appealing to religion, using relativism to justify accepting different truths to different situations

K. El-Ghariani $(\bowtie)$

Department of Hematology, Sheffield Teaching Hospitals Trust and NHSBT, The University of Sheffield, Sheffield, UK

e-mail: Khaled.el-ghariani@nhsbt.nhs.uk

J.-H. Dalle

Department of Pediatric Hematology-Immunology,

Hospital Robert-Debré, Assistance Publique-

Hôpitaux de Paris, Paris Diderot University,

Paris, France or explaining that ethical stands are unreasonably demanding (Blackburn 2001).

The most known ethical theories are Kant's deontological theory and Bentham and Mill's utilitarianism (Vardy and Grosch 1999). Kant argued for our duty to pursue a set of intrinsically ethical rules that can be universally applied. Ethics is the search for such rules. On the other hand, utilitarianism argues that an action or a rule is moral if their outcomes bring the greatest pleasure and happiness to the greatest numbers of people. No doubt, these theories would ignite an interesting discussion on transplant ethics but may not provide clear enough guidance to healthcare practitioners to help tackle the dilemmas that they regularly encounter.

During the last four decades, Beauchamp and Childress (2013) defended, and significantly developed, the four principles ethical theory for healthcare profession. These principles include:

1. Respect for autonomy: respecting the decision-making capacity of autonomous persons

2. Non-maleficence: avoiding the causation of harm

3. Beneficence: providing benefits as well as balancing such benefits against risks and cost

4. Justice: distributing benefits, risks and costs fairly.

According to Beauchamp and Childress (2013) 
Beneficence is the primary goal of medicine and healthcare, whereas respect for autonomy, along with non-maleficence and justice, sets the moral limits on the professional's actions in pursuit of this goal.

Ethical obligations towards patients (and sometimes their relatives) are well known to healthcare professionals. In the field of transplantation, management of donors adds another dimension to the ethical complexity. Two more areas of work are morally challenging, and although less well argued for, they are critical and have wide implications: firstly, the moral obligations of professionals to engage with fund holders, commissioners and insurers to ensure fair funding of service and, secondly, the ethical role of experts in the management, reporting and publishing of data and information to ensure accurate practice evidence to inform decision-making. Ethical practice requires one to apply the above four principles to all field of work, every time an ethical issue is raised. Transplantation practice is full with issues that can raise serious and sometimes disturbing ethical concerns. The following is a discussion of some aspects of the ethical implications of high-risk treatment, lack of enough funding for healthcare and issues with donor care.

\subsection{Ethical Challenges of High- Risk Treatment}

Blood and marrow transplantation is mostly used to treat life-threatening illnesses, but also it carries serious complications that are themselves life threatening. Resistance disease or a recipient with significant comorbidities can make transplant risks too high and brings risks of futility to the equation. Although guidelines and outcomes data are available in the literature, the application of such evidence may require the support of colleagues or other experts within a multidisciplinary team. This should help in striking the desirable balance between expected benefits and possible harm (the beneficence and the non-maleficence principles). Although risks may be too high, one ought to ask "is it the best option available for that particular patient with that particular disease?' (Snyder 2016). Moreover, the implications of undertaking a transplant procedure with limited benefits on resources and other patients ought to be considered. The limitation of transplant rooms, for example, may explain how a decision to transplant a particular patient could affect another.

A transplant procedure that carries only $10-20 \%$ chance of success can be a source of worry to staff as it brings the beneficence/nonmaleficence balance to a critical point. However, the other two ethical principles may help. What the patient wants to do? And will such a transplant jeopardise other patients care or face funding rejection? Obviously for a keen patient and supportive healthcare payers, the decision is less problematic. The balance of forces may be different in another situation with the same clinical ground. This brings uncomfortable variations into practice which can only be minimised by the development of constructive ethical discourse.

An unbiased list of options ought to be discussed with the patient (and possibly with their relatives and even healthcare payers). To obtain an autonomous consent, staff have to ensure that the patient has fully understood all options and has made a choice that is not influenced by any coercive factors. Obtaining such a valid consent requires arrangements and it will take some time and effort. This, however, not only meets our moral obligations but also has practical benefits, as a well-consented patient is likely to cooperate with the demand of treatment and work with staff to fight complications. Respect of autonomy dictates that patients are well informed about decisions that they make, and it also dictates that staff accept such decisions even if decisions sound counterintuitive. A selffunding patient who refuses life-saving transplant to save the money for their young children may pose difficult and very uncomfortable challenges to staff. This patient can be helped through exploring charitable funds for their treatment, but ignoring their autonomous decisions is not an ethical option. 


\subsection{Engagement with Funding Issues as a Professional Moral Obligation}

Establishing funding rules for transplantation treatment has been, on many occasions, considered the job of healthcare payers or insurers. Medical staff are involved in setting up guidelines, publishing data on outcomes and advising in some complex cases. However, an ethical assessment of the issue will put medical staff in the centre of decision-making. After all, healthcare payers and insurers will base all their decisions not only on medical information but also on the interpretation of such information as provided by medical staff. It is prudent to think that it is unethical that medical staff do not engage actively in this process. The same ethical desire that drives staff to treat illness and complications ought to drive their engagement in mending funding practices that do not meet patients' needs, as both issues are detrimental to patients' outcomes.

The respect to autonomy principle dictates involvement of patients' representatives in funding decisions. Most healthcare services have such an arrangement, and the job of the medical staff is to educate representatives to be able to make valid and informed decisions. The principle of beneficent, in this setting, can be applied by gathering, analysing and publishing good data to support funding decisions. Whilst publishing papers may have been considered as an option for academic progression, it seems that it has become an ethical obligation. Nonmaleficence means that delays in introducing new development in the field must be avoided. Transplant field is rapidly changing (for the better), and such delays could devote patients from a helpful treatment modality that could make a difference to them. The principle of justice is in the heart of healthcare funding. However, this ought to not mean 'sticking to the rule'. Most rules have legitimate exceptions and the job of the transplant physician to fight the corner of the patients in this regard. Some healthcare services support cord transplant but not the use of double cord, because of cost implications. This would disadvantage many adult patients with body weight that is too high for a cord blood unit to support. The desire to establish an ethical process of funding may have led the English National Healthcare Service to establish Clinical Reference Groups, including one for transplantation. This group is composed of a medical chair, eight other transplant physicians and three members to represent patient and public voice (NHS England 2018). Medical ethics is mainly seen as a direct issue between a professional and a patient. This discussion showed the ethical obligations of professionals outside the clinic and the hospital ward. This is obviously demanding but also more helpful to patients.

\subsection{The Ethical Issues in Donor Management}

Transplant donation is a fertile subject for ethical debate as all types of donation carry some moral concerns. These are mainly around respect of donor autonomy, risk of exploitation or possible harm to donor. Unrelated donors are supported by professionals other than staff who look after the recipient, and this is according to national and international guidance. Unrelated donations have some financial and reputational benefits to the donor registries. However, given existing professionalism and code of practice, this has rarely raised concerns. On the other hand, family donors receive less structured protection. The recent success in haploidentical transplantation means that more family donors will be involved, and so ethical grounds of such process needs to be established.

Whilst the balance of risks and benefits of most types of treatment offered to a particular patient can be established, a major dilemma in donor ethics is the fact that assessing harm and inconvenience to one person (the donor) in relation to expected benefits to another (the recipient) is highly problematic. Staff occasionally make the decision themselves and argue that some temporary aches and pains and minimal risks of ruptured spleen (G-CSF side effects) are acceptable risks to justify a life-saving donation, particularly to a family member. Staff position makes 'some 
sense', but it does not respect donor autonomy, and so it cannot be accepted as a universal rule that could be practiced widely, i.e. it lacks ethical grounds.

Child donors, pregnancies conceived for HCT and donation from a family member who lack capacity have been debated. Minor sibling donors require particular consideration as their autonomy is harder to prove. There is evidence that a child donor is subjected to both physical and psychological implications. This prompted (the) American Academy of Pediatrics Committee on Bioethics to recommend that five conditions are met to ensure morally justified donations from children (AAP 2010). These include lack of suitable adult donor, the expected benefit to recipient is reasonably high, strong relationship between donor and recipient, potential physical and psychological harms to donor must be minimised and, finally, obtaining parents' consent and child assent. Child assent and agreement are hard to confirm, and the availability of independent committee or assessor to look after such donors has been recommended.

Moreover, a family donation from an adult with full capacity can be morally challenging for two reasons. Firstly, not all family members want to donate. Some of them find the process too demanding, and if they were 'given the choice', they will rather not. The story of one such donor was in the news. A newspaper (the Daily Mail, UK) reported the situation using the following headline: 'Sentenced to die by my sister, leukemia victim refused her only chance of transplant' (Oldfield 1997). The sister refused to donate bone marrow because of the phobia of hospitals. The subsequent media debate led the donor to reconsider her position. This is a moral position that is hard to defend. Secondly, the health risks to family donors are not minimum or negligible. They are more likely to encounter significant complications than unrelated donors (Halter et al. 2009). Documented experience from unrelated donations cannot be used to advise family donors, and the comparison between harm to donor and benefit to recipient is even harder in the family donor situation. Many authors (van Walraven et al. 2010; Brand et al. 2011) attempted to raise awareness of these issues, and many argued that a system that is separate to and not influenced by patient care ought to be in place to manage family donors.

Transplantation, like other healthcare practices, requires an accurate balance between expected benefits and possible harm as well as valid patient consent. Given limited resources, the implication of one transplant on another ought to be considered. Given the life-saving and life-threatening nature of this modality of treatment, ethical issues with transplantation are likely to be challenging. Staff are expected to let patients decided for themselves. Moreover, staff ought to escalate complex issues to the legal system or more commonly to the ethics committee within their institution. In the European Union, Directive 2001/20/EC established ethics committees as an independent body to agree complex ethical challenges.

\section{Key Points}

- Clinical ethics teaches skills to tackle moral dilemmas but does not provide ready-made answers.

- Clinical ethics now extends, beyond patient clinician relationship, to donor care as well as engagement with fund holders and insurers.

- The four principles ethical theory (autonomy, beneficent, non-maleficence and justices) provides reasonable basis for moral assessment of ethical issues in most fields of practice.

- The donation process requires ethical vigilance. Family donors have high health risks and, given the potential social pressure, are not always autonomous.

\section{References}

American Academy of Pediatrics. Policy statement, children as hematopoietic stem cell donors. 2010. http://pediatrics.aappublications.org/content/pediatrics/125/2/392.full.pdf. 
Beauchamp TL, Childress JF. Principles of biomedical ethics. 7th ed. Oxford: Oxford University Press; 2013.

Blackburn S. Being good a short introduction to ethics. Oxford: Oxford University Press; 2001.

Brand A, et al. Uniform examination of stem cell donors. ISBT Sci Ser. 2011;6:160-4.

Halter J, Kodera Y, Ispizua AU, et al. Severe events in donors after allogeneic hematopoietic stem cell donation. Haematologica. 2009;94:94-101.

NHS England. NHS commissioning, Specialised, F01. Blood and Marrow Transplantation. 2018. https:// www.england.nhs.uk/commissioning/spec-services/ npc-crg/blood-and-infection-group-f/f01/.

Oldfield S. Sentenced to die by my sister. Daily Mail. 1997;1:5.
Snyder DS. Ethical issues in haematopoietic cell transplantation. In: Forman SJ, et al., editors. Thomas' hematopoietic cell transplantation. Chichester: Wiley Blackwell; 2016.

Thompson M. Ethical theory. 2nd ed. Coventry: Hodder Murray; 2005.

Vardy P, Grosch P. The puzzle of ethics. London: Fount; 1999.

van Walraven SM, Nicoloso-de Faveri G, Axdorph-Hygell UAI, et al. Family donor care management: principles and recommendations. Bone Marrow Transplant. 2010;45:1269-73.

West AA. Rulebook for arguments. 4th ed. Indianapolis: Hackett Publishing; 2009.

Open Access This chapter is licensed under the terms of the Creative Commons Attribution 4.0 International License (http://creativecommons.org/licenses/by/4.0/), which permits use, sharing, adaptation, distribution and reproduction in any medium or format, as long as you give appropriate credit to the original author(s) and the source, provide a link to the Creative Commons license and indicate if changes were made.

The images or other third party material in this chapter are included in the chapter's Creative Commons license, unless indicated otherwise in a credit line to the material. If material is not included in the chapter's Creative Commons license and your intended use is not permitted by statutory regulation or exceeds the permitted use, you will need to obtain permission directly from the copyright holder. 